\title{
The Strategies of teaching reform about English language courses based on network autonomous learning
}

\author{
Zou Meng \\ Jilin Business And Technology College
}

Key words: English linguistics; curriculum reform; network resources; autonomous learning

\begin{abstract}
English linguistics is one of the required courses for hospital staff, whichplays an important role in developing the doctors English language ability. This paperbased on years of teaching practice of English Linguistics and the investigation and analysis of 128 medical staff of a hospital based learning English linguistics. The purpose found English linguistics teaching under the traditional teaching pattern, reform suggestions on English Linguistics Course Teaching mode. With the development and improvement of information technology, multimedia and network teaching resources have been widely used in modern teaching, which provides a high degree of autonomy for English language learners. This paper advocate medical personnel use Web-based Autonomous Learning of English linguistics to promote the reform of teaching methods in English linguistics course, so which can improve the English teaching effect on the future construction of linguistics methodology, will also play a certain role in promoting in our country.
\end{abstract}

\section{Introduction}

Language is an arbitrary sign system for human verbal communication. The acquisition of language is a gradual process. Language is an art, it is a bridge of communication between people, is to maintain a good relationship between the bond, so that the study of language learning methods is essential. As an independent subject, English linguistics is one of the required courses for medical staff. This course can not only make doctors and nurses learn the basic theoretical knowledge of linguistics, but also more important, it can help students to improve the ability of independent thinking and language communication skills. However, in the traditional teaching mode, there are many problems to be solved in English linguistics teaching, this research is based on "A hospital medical staff to learn linguistic experiences on the basis of the investigation, through the analysis of the existing medical staff awareness and course on linguistics teaching problems, put forward specific reform program, in order to improve the teaching quality of English linguistics, the construction of the future of English linguistics methodology of our country will also play a role in promoting.

\section{The Existing problems in the teaching of English Linguistics}

Most of the National Hospital English language training courses, in the end all the time, many hospitals use” DoctorEnglish" as English teaching materials, the teaching material is very difficult in the first and second edition, which relates to the medical professional words more difficult. Although the some contents of the integration and deletion, but the medical staff to reflect the book is still very difficult. Due to the compression of the class and the teaching method, the majority of doctors and nurses have caused the fear of the course of linguistics and the difficulty to grasp the linguistic knowledge. The following problems are considered by studying the traditional teaching mode of English linguistics. 
The content of the course is very difficult and the abstract level is high. According to the analysis of 128 medical staff of a hospital in linguistics experience: $62 \%$ of the staff believed that linguistics is a boring and abstract subject, 59\% of the staff believed that many branches of linguistics, including knowledge and broader and more technical terms, it is difficult to understand the cause of this course. Only $12 \%$ of the medical staff thinks that linguistics is an art of speaking and full of curiosity.

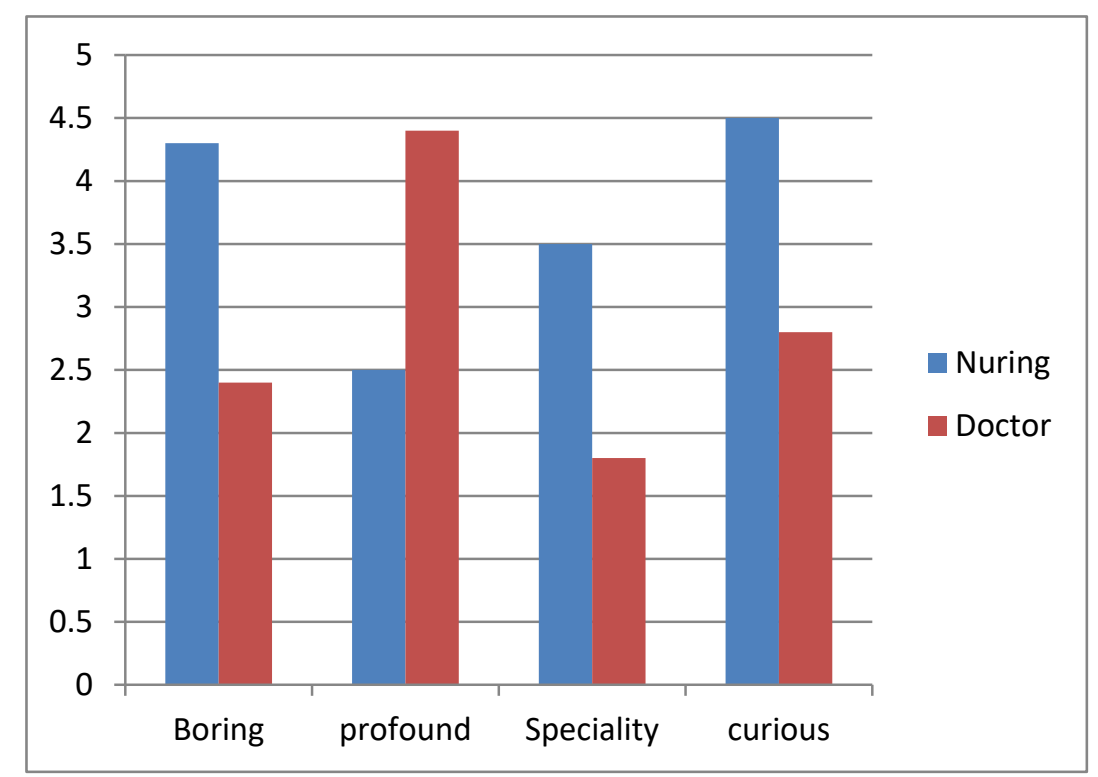

Figure 1 the Students' understanding of Linguistics

Teaching means is single and backward. Many hospitals has been followed by the traditional teacher centered knowledge infusion model in the teaching of English language teaching, has been ignored on the health care of the independent learning ability and innovation ability of the training. Most of the language teaching is the teacher lectures, notes, the actual language phenomenon and the practice of health care workers. Survey data show that linguistic teaching methods should be diversified, 59\% medical staff think that teachers should be linked with real life examples, the appropriate comparison between English and Chinese, and then let the medical staff free discussion and put forward their own opinion. This can make the complicated content simple, and also can stimulate the creative thinking ability of medical staff. 52\% medical staff thinks that should be more to increase the classroom interaction.it is not only can test the degree of knowledge of medical personnel to grasp the degree, but also can narrow the relationship between teachers and students. $25 \%$ staff believed that teachers should give them the opportunity to make medical staff personally prepare lessons and lectures. Thesummed up the teaching contents, making courseware, which can not only arouse the enthusiasm of the medical staff to study linguistics, also can cultivate the independent learning ability of medical staff. At the same time, $18 \%$ Health care workers believe that the classroom play language class lectures video can mobilize the enthusiasm.

The arrangement about curriculum is improper. The linguistic class is compressed to cause a lot of teachers cannot complete the task of teaching courses in Linguistics, because the course is an introductory course in linguistics. Teachers cannot properly focus, the final unreasonable assessment arrangements can not cause most of the attention to this course, many colleges and universities have adopted the study of language courses to test the degree.

Survey data show that $52 \%$ of the staff believed that linguistics should be divided into two 
semesters, but the school schedule only a semester, because the large amount of information, the content is high, the medical staff in a short time is difficult to digest. In this regard, $31 \%$ of the medical staff thinks that should increase the class, so that health care workers can be familiar with the content of the language, to really learn to apply the knowledge of linguistics to the actual life to improve their language training.

The knowledge is lack. The key to success of the teaching of linguistics is to a large extent depending on the efforts of the medical staff and teachers. Survey data show that there are many problems of medical staff in the linguistic study, such as lack of interest、 knowledge and lack of English reading or do exercises after class etc.. the survey data: $65 \%$ the medical staff that should be trained medical personnel to learn the language of interest, that interest is the best teacher. Secondly, 59\% the medical staff think that should do a good job before the preparation of the work, to sort out the difficult points. The process of finishing the point of knowledge can help to familiar with unfamiliar vocabulary, the accumulation of a certain vocabulary. Again, 30\% people think that the medical staff to practice and summary, repeated practice, in order to better understand the learning and mastering the knowledge of linguistics.

\section{The reform of English language teaching in the network era}

the modern educational concept has changed radically, which emphasizes that modern teaching should be based on health care workers as the main body, teachers to enhance the ability of independent learning and innovation of medical staff. It requires the diversification of teaching methods and the modernization of teaching techniques. All these are the ideas and technical preparation for the reform of English teaching.

The teaching idea is innovation. The change of teaching idea is the premise of the teaching reform of all courses. the traditional teaching mode has lost its original important position in the teaching. Modern teaching needs the teacher centered teaching leading to the teachers, medical staff as the main teaching change from the knowledge centered teaching to impart knowledge. Therefore, the modern teaching concept should make the teachers aware of all the teaching activities should be the center of the medical staff in the classroom, strengthen the main body position of the medical staff, training of medical personnel's self-study ability and innovation ability. Compared with the traditional "teaching mode" mode, the "discussion" mode, which takes the medical personnel as the center, has put forward higher requirements for both the teachers and the learners. Teachers not only need to update the English linguistic knowledge, but also a good grasp of modern teaching technology to design each class, including health care activities, learning resources, curriculum setting, difficulties.

The network teaching technology is improvement. the network based teaching has changed with each passing day, whichassisted instruction to enrich the teaching resources, multimedia teaching content, the interaction between teachers and students to make up for the limited amount of information in the traditional classroom teaching, a single form and so on. The use of network resources, teachers and students can access a large amount of information related to the teaching materials, to broaden the field of study. In recent years, many scholars have studied on the application of network multimedia technology in the teaching of English Linguistics in the present linguistic teaching should make full use of multimedia and network technology, makes the language teaching to "Inquiry Learning" instead of the traditional "knowledge type" mode, training medical personnel's independent thinking ability, self-learning ability and research innovation ability. 
Language teachers can prescreen the linguistic resources on the network, establish the teaching resource database, and provide some help for the medical staff.

Update the language teaching materials and optimize the teaching content. According to the survey, 63\% the medical staff found that teachers should optimize the linguistic content, select the heavy and difficult to explain. There are a lot of people think that should update the language teaching materials, such as the deletion of some of the more difficult content such as logical semantics, etc. Therefore, it is an important way to update the English language teaching materials and optimize the teaching content in a timely manner.

\section{Conclusion}

This paper summarizes and analyzes the basic problems of linguistics course for English major teaching hospital and puts forward the reform scheme of the network information age, that is to say, in the course of linguistics theoretical and abstract, high degree of difficulty, and with the class of compression and single method backward situation teaching, new teaching methods on the teaching of linguistics is proposed. This paper focuses on the application of self-regulated learning in English language teaching, linguistics explains the teachers and staff how to cultivate medical personnel the ability of autonomous learning in the multimedia network with the help of information technology.

\section{References}

[1]Holec, H. Autonomy and Foreign Language Learning[M]. Oxford:Pergamon Press, 2013.

[2]Chen Xiaoxiang, Zhang Xiyang. The necessity and feasibility of autonomous learning for English Majors in Colleges and universities[J]. Journal of Xi'an College of Foreign Languages, 2014 (3). 